\title{
AUDITORY VS VISUAL STRATEGIES AMONG KURDISH LEARNERS OF ENGLISH LANGUAGE
}

\author{
Areen Ahmed Muhammed \\ Charmo University, College of Education and Languages, English Department, Chamchamal, \\ Kurdistan Region, Iraq \\ E-mail: areen.muhammed@charmouniversity.org
}

Received: 21 May 2020

Accepted: 08 June 2020

\begin{abstract}
When it comes to the case of Kurdish universities regarding teaching styles and methodologies plenty of obstacles and barriers anyone can face not only due to the low level of the majority of the students; but also other factors like religion, interest, grading system, and most importantly low number of references on the subjects area can be the core cause of the issue. One of those points which drove the researcher to write on the common issue was due to the reason that the researcher could not find enough and adequate sources on the subject area; hence, the researcher tried to enrich the referencing system of Kurdish studies of English language in one hand and provide and broaden the horizon of other nationalities regarding Kurdish EFL learners of English and in English taught programs. As a matter of fact, through decades many scholars have been conducting studies on different teaching methodologies and they provided up to four different styles of language teaching. Apart from that, many other linguists enlightened their studies on Far East Asian countries or European. Even if some Middle Eastern studies were taken into consideration; but still, none can be found in the case of Kurdish university students. The current paper was conducted on English department of Charmo University with a total number of 34 participants from three different stages.
\end{abstract}

Keywords: Kurdish students; Visual strategy; Auditory strategy; Gender

\section{Introduction}

Throughout history, many scholars tried to find the best strategies for different learners to absorb a vast amount of information in learning or using a second language. Fortunately, the experts could find some strategies and divided them into four types; visual, auditory, kinesthetic, and tactile learning. Normally, these strategies are used for diverse learners to enhance their learning ability. However, luckily, this paper covers the detail of both visual and auditory learning only since it is very common among Kurdish University learners. The aims of this paper can be shortened into two vital points. First, it is to shed some lights on both types of learners (visual and auditory) and their characteristics. Secondly, it is to show the use of an appropriate style for each kind of learners and their suitability on the learners.

\section{Literature Review}

\subsection{Auditory and Visual Learning Concept}


The term "visual" learning has been defined by many scholars; although, most of their definitions are quite similar to some extent. Recently, Cook (1994, 2004), Felder (2010), and Witterveen (2009) are on the belief that visual learning is one of those strategies in the learning process, which involves explaining any language through showing pictures, diagrams, maps...etc. Naturally, the information that is presented visually helps the students to remember things easily. Besides, the activities performed in the classroom using the visual sense of the students will assist the teacher to achieve better results. Arguably, Dwyer believes that visual learning improves and progresses the learners' understanding and the ability for an image in terms of reading, writing, and thinking; as he quoted "the capacity to understand reading, writing, images, and to think and to learn in terms of image". (Dwyer, 2004:3)

Another type of learning strategies is known as auditory learning. The term is defined by Cook (1994, 2005), Hayes (2012), and Lenka (2011) as the process in which triggers the sense of hearing near the learners inside the classroom. The process includes listening, discussion, verbal communication, and activities, such as songs and music with rhyme and rhythm, and $C D$; whilst, the students are engaged with a task inside the class. Generally, to activate the hearing sense of learners each of tone, pitch, and loudness are very essential; since hearing sounds are the most sensitive and effective method to EFL learners. Apart from the above points, dictation could be a good example for the above concept to be accounted for. Besides, through listening skill, the student will improve faster besides language development. Reluctantly, the leaner in such above activities will use each of two skills (reading and listening) in his/her learning process separately. Consequently, the results will be more influential to the students. It is in vital importance to co-use each notion in teaching any skills of any language; as LLC says that "visual and auditory is the interaction of learning styles with reading methods (silent and auditory)" (LLC, 2009: 49).

\subsection{Scholars' View Points}

Needless to say, scholars have tried a lot to help teachers in presenting a vast amount of information in the classes. Meanwhile, the information should be absorbed by the learners; thus, they have put many different learning strategies. In addition to this, Chiya believes that each learner has a specific style to understand and gather information. Hence, teachers should be careful in analyzing students' learning styles. As it was known earlier that diverse learners require diverse learning strategies. Likewise, these different kinds of models will determine learner's preferred learning style; as Chiya quoted "keen teachers realize students in having different learning preferences" (Chiya, 2003: 1).

In Willamette University, in the USA, an experiment was carried out on Japanese and American learners to find the best method to teach English. The data for learners revealed that visual and auditory learning styles are on the top of the list to learn the English language. They have a huge role in increasing students' awareness. Importantly, both (visual and auditory) encourage learners to be active and participate a lot in classes (Heuser, 2007).

Naturally, in most college classes, the majorities of students listen to lectures and read the information which is written by a marker on the board, read materials, textbooks, and handouts that implies for auditory learners. Unfortunately, most learners are visual learners. This means that students cannot achieve information as much as they wish to (Chiya, 2003). According to some researchers, the information, which is presented visually in the class, is very easy for the learners to memorize and remember. Moreover, good learners are those who can acquire the information which is presented either visually or through auditory. However, using auditory styles are best for those students who are learning through hearing, 
because they learn better when they listen and discuss the knowledge in the class among each other's and colleagues. Moreover, the main aim of language teaching for students is to speak out and write in English as a Foreign Language (EFL). Therefore, it is very significant that the style of learning should be chosen wisely; because if learners do not like that specific strategy they cannot enjoy learning process then it would be just a waste of time. (Eslami, 2007, and Ahmad et al., 2009)

Namely, it has been mentioned earlier that different learners require different learning strategies. As in Japan, some learners were helped to master English. Subsequently, some of them learned English through presenting slides visually which was based on their personal experience and background. Nevertheless, the others learned via listening to the lyrics of popular singers. Sadly to say, many learners around the world do not study English effectively, since lecturers do not use various styles or the style which suit with specific students; on another hand, most of them do not have access to a wide verity of activities. (Ahmad et al., 2009)

In another case which shows that if the style does not match the student's interest then the learners and the teachers will face difficulty. As Chiya shows, in the research which was conducted in China, the students preferred visual learning strategies to learn on other styles, but the teachers were interested in auditory strategies to teach. The auditory teachers were asked to teach visual learners by using their auditory style with visual learners. Consequently, the learning process was not very successful, especially for the students. Thus, the teacher should be very sensitive toward students' learning style, because it is the most crucial when it comes to learning a new language. Furthermore, they should seek for the activities, which will be useful and keep balance in the learning process. (Chiya, 2003)

Another paper was written on Japanese and Asian learners to see whether the culture will determine the types of learners or not. The participants from America (the US) participated in a class discussion using the auditory style. The outcome was that Asian learners were auditory learners because they could easily express themselves and talk about topics, which they have heard. In contrast, Japanese learners were visual, since they could easily talk about topics that they have seen. (Han, 2007)

Another estimation, which was done in Iran/Shiraz University, to know which style is more preferable among learners. The students were introduced to different learning methods, such as reading, listening, taking notes, and witting down ideas on board. Although all of them are important in the field of teaching, it turned out that reading and taking notes frequently will enhance the capacity of the students. However, the majority of them were agreed on the visual learning style. More importantly, the result interpreted that learners, who are involved in classroom interactive and participant, learn more than they just sit and see what is going on in the class (Riazi, 2007).

In short, Visual and auditory learning styles have an important role in learning English for academic purposes. It is the key concept that the style should correspond with learners' preference. Most of the projects showed that auditory learning has more significance than visual. However, visual and auditory are designed correctly to develop students in studying, reading, and writing skills. (Ahmad et al., 2009)

\subsection{Gender and Style in Selecting Strategies}

Is it necessary to change the style according to different genders? The scholars and methodologists have different opinions regarding the answer to this question. Each of them has answered the question based on the results of their experiments (Mahmud, 2014). 
Commonly, male and female have different ways of communication (Yule, 2010). Due to this reason, they have different ways to learn the English language. Therefore, teachers should treat both genders carefully and equally in classes. Abdul Said indicates that in one of his investigation that female learner uses her auditory senses to learn because she learns through listening to the material(s). On the contrary, male learners receive knowledge by taking notes and reading (Abdul Said, 2014). A research was carried out in Anglo American university, in America, to show whether male or female learners need various styles or not. The documents indicated that female learners need various styles than males. As Abdul Said quoted "female students were significantly more likely to prefer a multimodal learning style and, conversely, male students were significantly more likely to prefer an immoral learning style" (Abdul said, 2014: 160).

Moreover, some writers examined some students from Oxford University to test the ability of both genders in learning. The outcome showed that female learners anticipate social and interactional strategies more frequently. This led to state that girls have more capacity to learn English than the boy in learning English because girls have the verbal ability, which means they can speak and express knowledge easier (Booth and Bitan, 2008). However, some authors investigated on Asian and American learners and claimed that they could not find any effects of gender on learning style. In addition to this, several types of research were implemented in Arab countries. They were unable to find a significant difference between female and male in learning English. (Abdul Said, 2014)

Moreover, in the United States / Northwestern University a questionnaire proved that females and males use different parts of the brain while learning a language. Therefore, the language process works harder for girls than boys, because girls always feel shy and they use a lot of methods that confuse them. According to another opinion, it is easy for male learners to obtain the information from both teaching styles (auditory and visual), because they are better in visualizing and hearing information which is provided in the class by the tutors (Booth and Bitan, 2008). It is chief importance for the instructors to stimulate students' achievement by using different and mixed methods while offering the information because they learn differently according to different genders as well. Certainly, learning style plays a vital role in students' accomplishment, especially for girls that they are more sensitive than boys and they feel shy with the opposite gender; well, females always feel comfortable with female genders. In brief, boys and girls communicate differently, since both own different characteristics; for instance: girls are more polite than boys and they have more shyness than boys. Therefore, they both need different ways of teaching. Additionally, most of the researchers are on the belief that has been explained in details with clues above.

\section{Methodology}

\subsection{Research Method}

Goddard and Melville (2004) recognize the research method as a way of answering unanswered questions for the topic that was selected by the researchers. The research method is a path for researchers to show the methods which they have relied on during the process of composing. Accordingly, the investigators choose the method of data collection to explain the problems and the results.

\subsection{Research Questions}

The current paper aims to answer the following research questions:

1. What is the role of teacher and methodologies in solving learning problems? 
2. What is the role of each strategy in drilling knowledge?

3. How different genders' opinions on choosing different styles may change?

4. What could be students' recommendations and solutions in choosing a specific strategy?

\subsection{Participants and Methods}

In this research, thirty participants participated in the questionnaire and four participants in the interview. The researcher chose them from different stages and genders to achieve variable opinions. Ten participants were chosen from each of the second, third, and fourth-year students. Then, two of the participants were interviewed in the second stage, and two others were interviewed in the third stage. They were students of English Department / Charmo University. Furthermore, seventeen males and seventeen females have participated.

In this paper, the researcher used two kinds of methods, which are questionnaire and interview to achieve different opinions about using different strategies on different students.

\section{Presentation, Analysis, and Discussion}

\subsection{Presentation and Analysis of the Data}

\subsubsection{Questionnaire Results and Analysis}

This part contains the presentation of the collected information, which is about using auditory and visual strategies in EFL classes. Additionally, this section presents the results of the questionnaire and background of the questions. It clarifies the reasons behind these troubles. Likewise, it will demonstrate those reasons, which may decrease the cause of these problems. Gender: In this research paper, the researcher has received a different outlook from different genders as clarified in section three. Half of the participants were males and the other half were females (equal division).

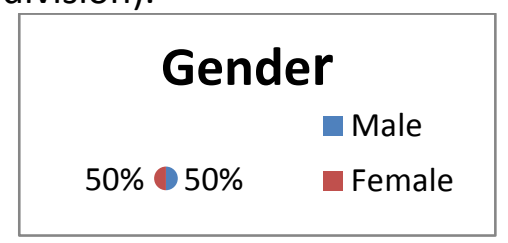

Figure 1. Gender

Statement One: The first statement is about "Students, who are learning better by reading what the teacher writes on the board". It can be used for auditory and visual learners. There have been some different views on this question; as (16.6\%) of the participants have chosen strongly agree. Additionally, half of the participants (50\%) have chosen agree and (20\%) of the participants have selected neutral. Furthermore, $(13 \%)$ of them chose to disagree, but none of the students $(0 \%)$ tick strongly disagree.

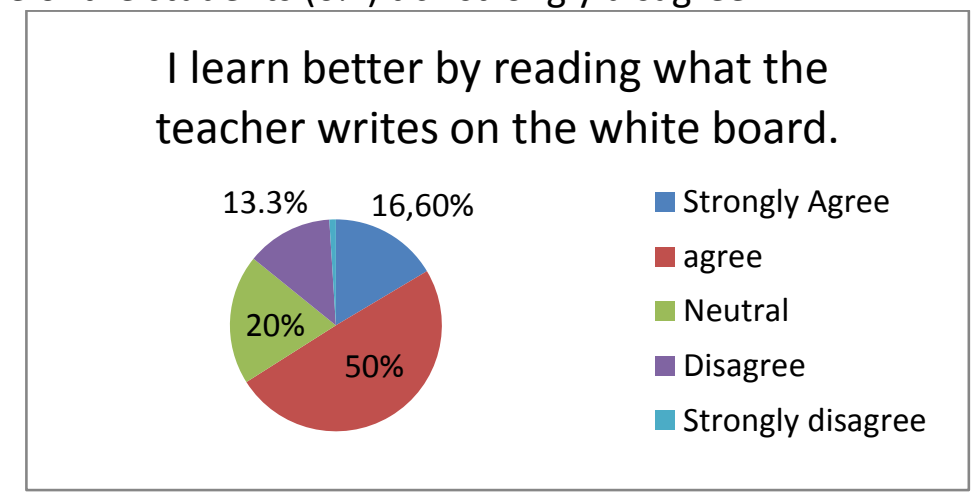

Figure 2. Statement On 
Statement Two: The second statement is about "Students who remember things that they have heard in the classes better than the references they have read". It implies that the participants have different ideas about this question; as the matter of fact, $(26.6 \%)$ of the participants have chosen strongly agree, $(30 \%)$ of the participants chose agree and neutral consequently, $(10 \%)$ of the students have chosen disagree, and $(3.3 \%)$ of them took the strongly disagree option.

Statement Three: For the case of statement three as it shows that "Students learn more in class when they participate in the related activities". There are some different views concerning this statement in which; (43.3\%) of the participants have chosen strongly agree option, (36.6\%) of them have chosen the agree option, (13.3\%) have selected the neutral option, (6.6\%) of the participants have chosen disagree option; whilst, none of them $(0 \%)$ ticked the strongly disagree.

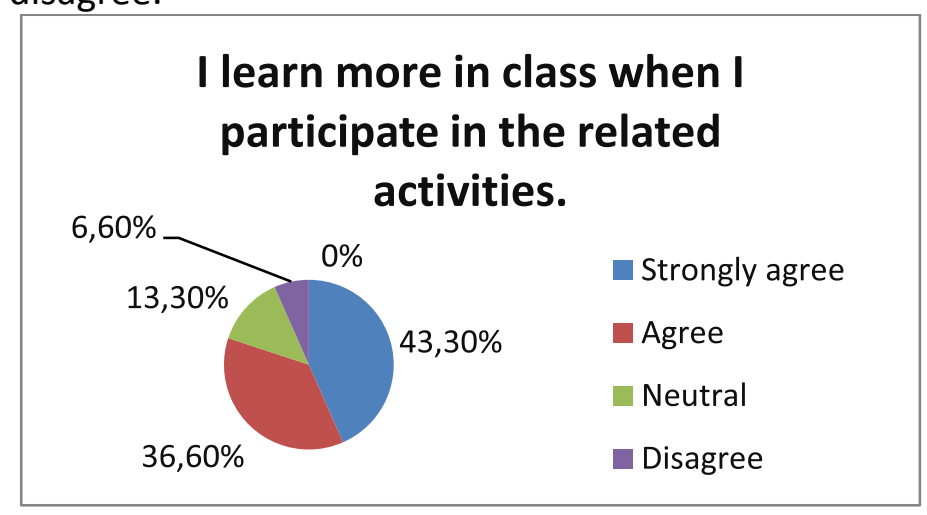

Figure 3. Statement Three

Statement Four: Regarding statement four, it is exposed that "Learners can learn more by reading textbook rather than by listening to someone". They showed different ideas about this statement; as (16.6\%) of the participants have chosen strongly agree and agree consequently, $(20 \%)$ of the participants chose the neutral choice, $(40 \%)$ of the participants ticked the disagree option, and (6.6\%) have selected the strongly disagree choice.

Statement Five: For statement five which is about "Students who find that it is useful to read out loud when reading the textbook" different results have been collected among the participants. (23.3\%) of them have chosen the strongly agree. $(40 \%)$ chose the strongly agree option. Also, (33.3\%) of the participants selected neutral, $(3.3 \%)$ have chosen disagree, and none of them (0\%) ticked strongly disagree.

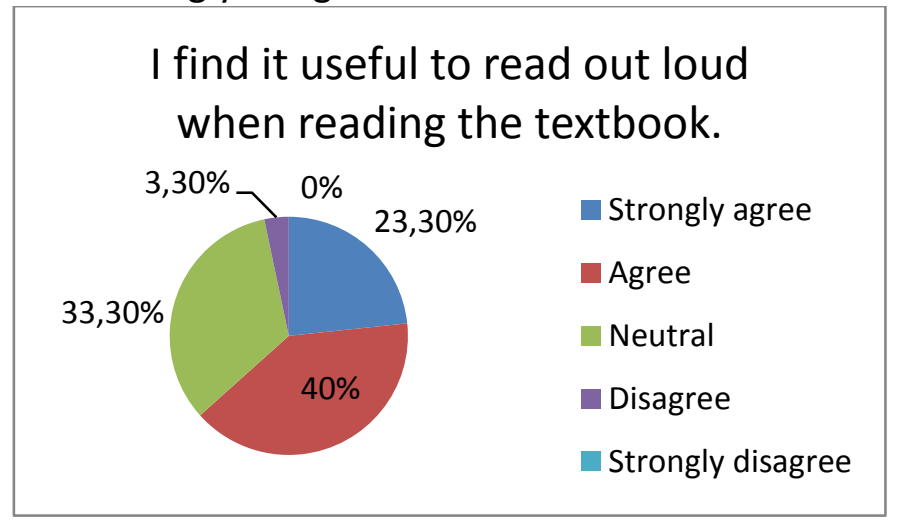

Figure 4. Statement Five

Statement Six: Statement six is about "Participants who participate in group work, pair work, or ask questions in class they learn better" because it has high-quality and utility in the 
process of learning any language. Additionally, it should contain both of the skills for the different students. Almost half (46.6\%) of the participants have taken strongly agree option, $(30 \%)$ have chosen agree option, $(16.6 \%)$ of them have selected the neutral. By contrast, only (6.6\%) of the participants chose to disagree, and none of them $(0 \%)$ chose the strongly disagree.

Statement Seven: For statement seven, this includes those "Students who learn better in class, while they listen to others when they ask or speak". Almost one-six (16.6\%) of them have chosen strongly agree, while one fourth (36.6\%) chose to agree and neutral option, but a small number (6.6\%) have chosen the option to disagree, and only (3.3\%) of them ticked the strongly disagree choice.

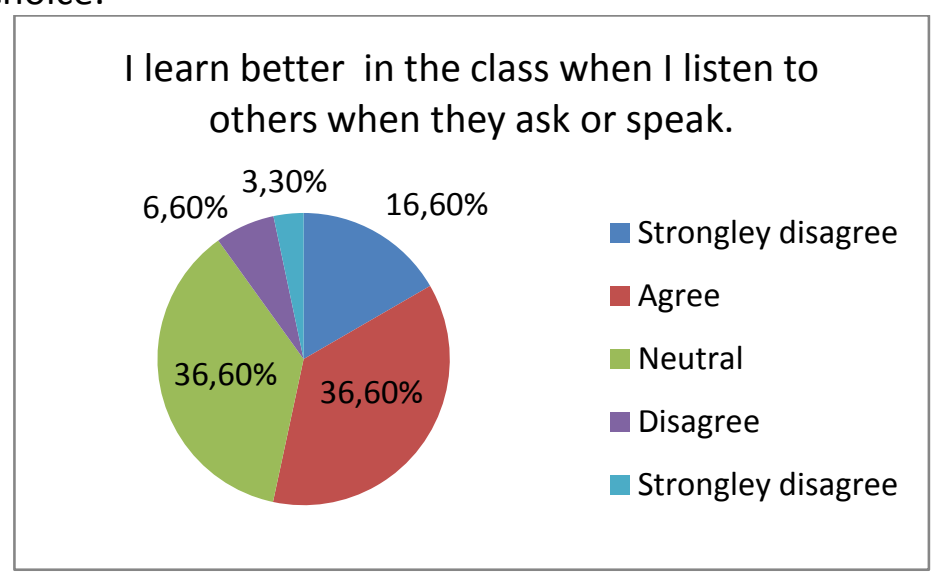

Figure 5. Statement Seven

Statement Eight: Statement eight is about those "Students who can understand better in class when they participate in role-playing". The researcher acquired some opinions; more than one-quarter $(30 \%)$ of the participants have chosen strongly agree, half of the students which covers (50\%) of the participants ticked agree, (10\%) of them have chosen neutral, $(6.6 \%)$ of the participants chose disagree, and almost none (3.3\%) of them ticked strongly disagree.

Statement Nine: As for statement nine, which is about "Students who would prefer to listen to the lecture rather than reading a coursebook", there are some different agreements. Adequately $(17 \%)$ of the participants chose strongly agree, almost half $(40 \%)$ of the participants have chosen the agree option, (30\%) of them chose neutral, $(10 \%)$ of them ticked disagree, and only (3\%) of the participants selected strongly disagree.

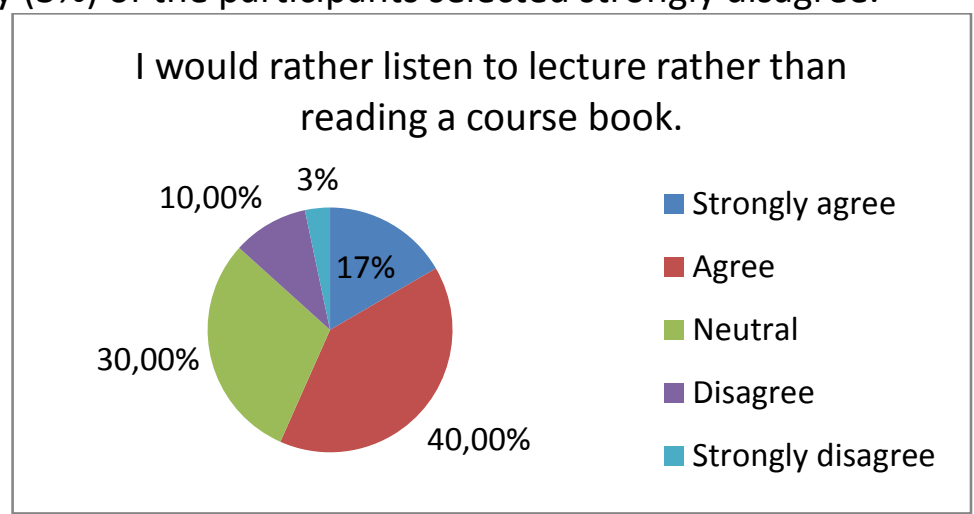

Figure 6. Statement Nine

Statement Ten: As for statement ten which is about "Students, when they read instructions, they remember them better". It focuses on visual skill; none of the participants 
$(0 \%)$ chose the strongly agree option, almost half of them $(53.3 \%)$ have chosen the agree choice, $(33.3 \%)$ of them have chosen neutral, $(13.3 \%)$ of them chose to disagree, and none of the participants $(0 \%)$ selected strongly disagree.

Statement Eleven: This statement explains that "Students prefer to learn by doing exercises and drills in the class". A quarter of the participants (26.6\%) chose the option (strongly agree), almost half $(46.6 \%)$ of them have chosen the agree option, $(13.3 \%)$ of the participants chose neutral, (10\%) of the participants have chosen disagree, and almost none (3.3\%) selected strongly disagree.

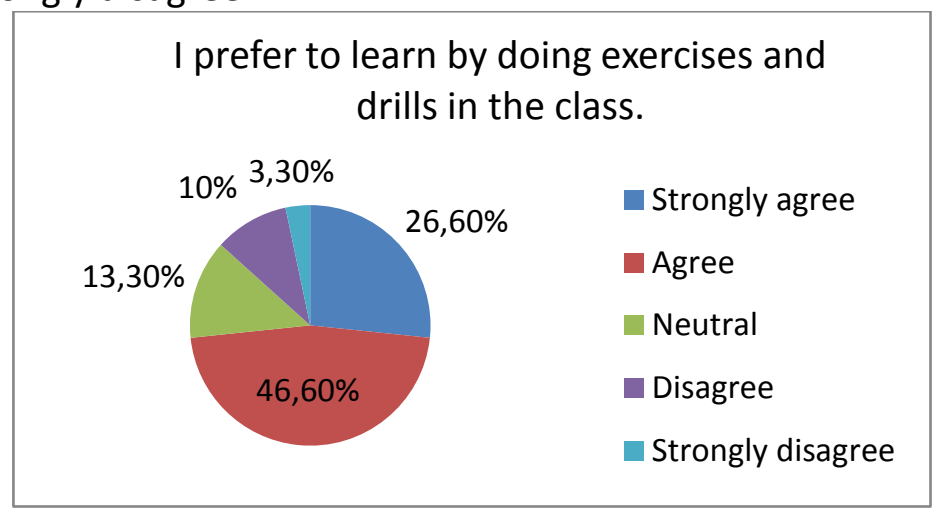

Figure 7. Statement Eleven

Statement Twelve: As for statement twelve, which is about "Students who have preferred the visual information, rather than the information they hear". There would be seen some different views. (40\%) of the participants chose the option strongly agree, a quarter of them $(23.3 \%)$ have chosen agree, $(36.6 \%)$ of the participants chose the option neutral, and none $(0 \%)$ chose to disagree and strongly disagree.

Statement Thirteen: Statement thirteen proposes that "Students can get benefit more from computer lab classes than usual classes". The data shows that $(23.3 \%)$ of the participants have chosen strongly agree choice, a quarter of them (26.6\%) chose agree option, $(30 \%)$ of the participants chose neutral, (13.3\%) of them have chosen disagree choice, and lastly (6.6\%) of the participants selected strongly disagree option.

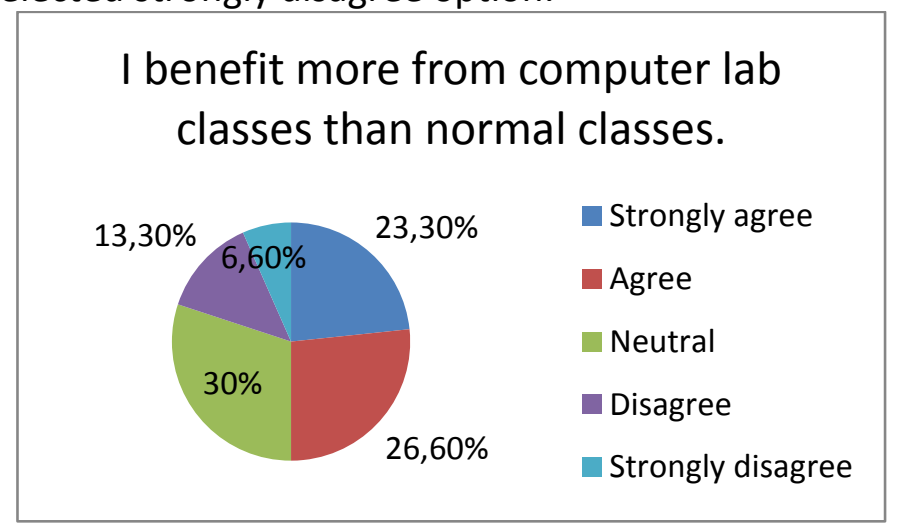

Figure 8. Statement Thirteen

Statement Fourteen: In statement fourteen which is about "Students who can learn better in the class when the teacher gives a lecture"; $(13.3 \%)$ of the participants have chosen the option strongly agree, almost half $(40 \%)$ of them chose to agree choice, $(33.3 \%)$ chose the option neutral, $(10 \%)$ of the participants have chosen the disagree option, and (3.3\%) of them selected strongly disagree choice. 
Statement Fifteen: For statement fifteen which is about "Students' learning a new skill, I would rather watch someone demonstrate the skill than listening". Almost one-fifth (16.6\%) of the participants have chosen strongly agree, $(40 \%)$ chose agree on option, $(23.3 \%)$ of them have chosen neutral, (16.6\%) have chosen the option to disagree, and almost none $(3.3 \%)$ of them ticked strongly disagree choice.

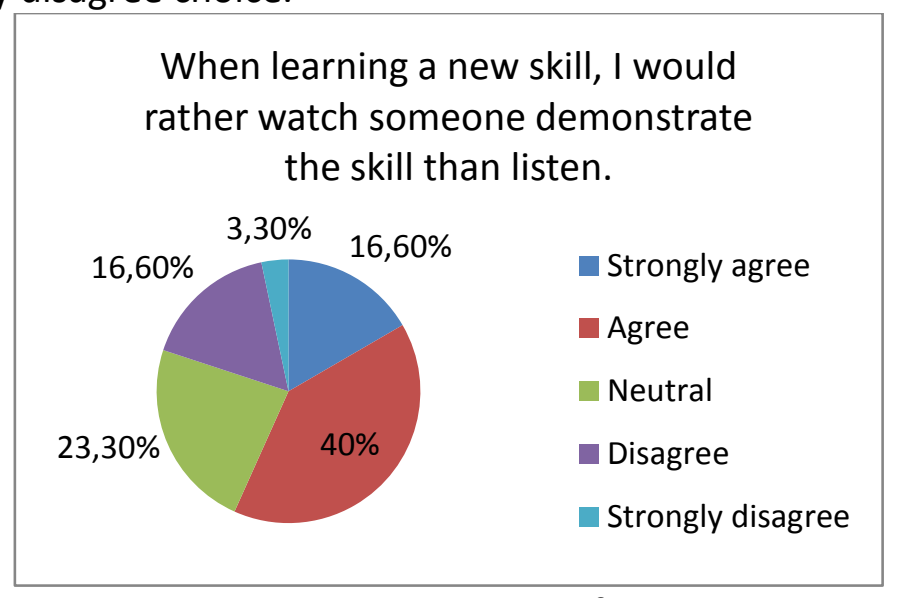

Figure 9. Statement Fifteen

\subsubsection{Interview Results and Analysis}

Four Kurdish university students participated in this part. Throughout the interview, the participants felt free about giving their views on the subject. Furthermore, the students were asked whether they are aware of the advantages and importance of auditory and visual skills. Moreover, they were also selected according to different genders and it was based on participants' gender in choosing their learning styles for the subjects. Another question was about the effect of culture on each auditory and visual skill. Besides, the next question was about their understanding of the subject through the use of different styles. Finally, the last one was about suggestions of the participants for the students in choosing appropriate style dependently.

The students were asked several questions. Firstly, three of the participants have the same opinions about the advantages and importance of auditory and visual skills in learning EFL. According to their opinions, the students and teachers have to be aware of each strategy and technique separately, because each skill has its influence in drilling knowledge. Likewise, visual skill tries to realize information while the learners can comprehend the information well, and the learner can speak with and understand native speakers. By contrast, the last student had a different point of view; s/he did not know the exact importance of each technique that is why s/he may not perform them in the process of learning precisely.

In another question, the participants were asked whether the different gender has a diverse style or not. The two interviewers who are a male and a female, they disagreed with it because they thought that the visual skill is the best style for both genders; meanwhile, when the information is presented visually the students can receive and gather information more from those ideas that are seen. However, both of the interviewees were different in genders. They did not confirm this because of both of the styles which are important for the two different gender characteristics in EFL learning via listening and watching the $\operatorname{program}(\mathrm{s})$, reading, and lecturing.

Concerning another question, half of the interviewees believed that visual learning is important when the teacher presents some videos and slides before the lecture for visual learners. On the other hand, the auditory style is better if the teacher has a loud voice and 
prepares some recordings and songs because hearing sounds are very sensitive and it is effective for auditory learners to learn a language in the process of learning.

Including the last question, the students were asked to give recommendations to other students in the English department and those who want to learn English as one of the students agreed with having students' suggestions. S/He suggested that "everyone has his/her style for teaching which is practised by the teacher while the majority of learners have to select visual skill as a favourite one, to understand easily because it gives more motivation and participation in the class". Another female interviewee had a different recommendation, she suggested that "everyone should choose the auditory style because hearing sounds are more influential and prominent for learning any language"; moreover, according to this participant, it helps them to speak with native speakers and understand them well. Furthermore, the last two interviewees who had the same recommendations, they agreed with the importance of both skills for all learners; meanwhile, "everyone has to know about all the pedagogies of learning because each skill has a vital role in different sections of the learning process". The learner can prefer a specific skill which is more suitable and advantageous with his/her learning style because each person can be good in one skill or style more than others.

\subsection{Discussion of the Research Questions and the Main Findings}

\subsubsection{The Role of Teacher and Methodologies in Solving Learning Problems}

Regarding those findings that the researcher had received, the teacher should be careful (aware) about all strategies which are being used on learners; besides, for each learner, the teacher should use a specific style to teach, considering how s/he can understand well. Meanwhile, the teacher has to have his/her role in using different styles for different students to drill knowledge. According to one of the interviewees "the teacher has to prepare slides, videos, and lectures before the lecture". In contrast, (50.3\%) of the participants agreed with giving texts and slides by teachers to decrease the problem, and only (13.3\%) disagreed with it. Furthermore, the teacher should practice different tests and activities to enhance knowledge in class considering learners, the learner also can learn better when a teacher uses computer lab class than usual common class, in which (49.9\%) agreed with it but only (9.9\%) disagreed. Besides, the teachers do exercise in the class which has the most beneficial result on learners that (73.2\%) of the participants agreed with it and (13.3\%) disagreed. It tries to solve the problems that the learner has with using that style which is used by the teacher; as Riazi (2007), and Chiya (2003) supported the notion of a teacher acts in this way almost all the information can be obtained by learners.

\subsubsection{The Role of Each Strategy in Drilling the Knowledge}

Considering another estimation which is achieved by the researcher, every skill has its influence; temporarily, presentation of visual and auditory skills have vital roles in the improvement of learning any language, because each of them has a major position; likewise, visual skill helps the learner to be good in reading and spelling...etc. Additionally, (63.3\%) of the participants agreed with the idea of visual understanding and only (36.6\%) disagreed. Additionally, the auditory skill may improve listening and speaking of the learner as $(56.2 \%)$ of them confirmed it and only a small number as (9.9\%) of them disagreed. However, every kind of pedagogies must be included equally in the class because giving many varieties of activities to the class has their importance to EFL learners, to be more active, in which it is found by Heuser (2007). Furthermore, LLC (2009) agreed with it while he selected reading skill (readout 
loud) because it contains both skills. In contrast, most of the participants agreed with using just visual skill for all learners as Riazi (2007) mentioned the idea of selecting visual student(s).

\subsubsection{Different Genders' Opinions on Choosing Different Style}

In this research, the researcher talked out that different genders have diverse styles to learn any language; as for the moment, the males have different styles compared to the females, which was found and can be supported by the study of Eslami (2007), and Ahmad (2009). Moreover, each learner especially who is different in gender selects a single style to achieve more useful criteria in the process of learning. Moreover, females imply deferent styles more than males which make them face confusion as it was found by Abdul Said (2014). In contrast, it is against the ideas of the participants since most of them selected visual skill, which is more important than others, as Yule (2010) does not confirm it and he thinks that both of them are beneficial to learn English via listening songs, reading, watching...etc.

In another approach, everyone should suggest a style in the language learning process. In which there are different opinions; considering the two interviewees, the learners should know about all skills or styles, also they have to choose a specific style which they think is suitable for them, while the majority of the participants agree with it and the idea can be confirmed by the work of Chiya (2003). In another participant's point of view who believed that every learner should choose the auditory style because it is the most interesting technique. On the other hand, most of the participants agreed with visual skill. In contrast, Booth and Bitan (2008) disagree with it because each skill should be practised in the process of learning languages.

\section{Conclusion}

This research deals with the investigation into the use of auditory and visual strategies by university EFL learners in Kurdistan; especially for undergraduate students. After finalizing the project, the researcher reaches these influential points:

1. According to the most scholars who are mentioned in this paper and the participants who are participated in this research, visual and auditory learning are the most important strategies in the process of learning, but visual one is more beneficial than auditory.

2. Teachers should practice different styles for diverse students because each learner has his/her style to learn.

3. The female learners use too many different styles which have a negative influence on them because they will have confusions.

4. Teachers who apply multiple strategies are considered as good teachers because the students receive benefit from those activities and strategies which are used by the teachers.

5. The researcher recommends future scholars to conduct research on the effects of culture on learning style(s) which is out of space in this paper. Another suggestion, as it is intended to give to the next researchers is that they should care about the psychological and social barriers and conflicts of the learner.

\section{References}

Ahmad, F.; Milalic, A.; and Mohd Shah, F. (2009). Perceptual Learning Styles of ESL Students. European Journal of Social Science, 7(3), 23-30.

Booth, T. and Bitan, R, J. (2008). Gender Differences in Language Appear Biological. Neuropsychologia, 10(2), 45-70. 
Chiya, S. (2003). The Importance of Learning Styles and Learning Strategies in EFL Teaching Japan. Global Journals, 8(1), 37-45.

Cohen, L. (2007). Research Methods in Education (6 $6^{\text {th }}$ Ed.). Routledge: New York.

Cook, C. (1995). Learning Style: Teaching Everyone God Gave You to Teach. Marlene Le Fever: U.S.

Decapua, A.; Verna, M. A.; and Wintergerst, A. C. (2002). Conceptualizing Learning style Modalities for ESL/EFL Students. System Pergamom, 3(1), 85-106.

Dwyer, D. (2004). Visual Literacy. Southern University Press: Carbondale.

Eslami, Z. R. (2007). Discourse Markers in Academic Lectures. Asian EFL Journal, 9(1), 10-34.

Felder, R. (2010). Learning Styles and Strategies. North Carolina State University: US.

Goddard, W. and Melville, S. (2004). Research Methodology: An Introduction (2 ${ }^{\text {nd }}$ Ed.). Blackwell Publishing: US.

Han, E. (2007). A Study of EFL Students' Perspectives. Asian EFL Journal, 9(1), 67-96.

Hayes, D. (2012). Developing advanced Primary Teaching Skills. Routledge: Birmingham City University: UK.

Heuser, L. (2007). Linked Intellectual Learning Activities for Undergraduate Japanese and American Students. Asian EFL Journal, 9(1), 13-25.

Lenka, O. (2011). The Use of Pop Songs in the EFL Classroom. Verlag Gmbh: Hamburg.

LLC, Q. (2009). UMI. United States Code: East Eisenhower Parkway.

Mahmud, M. (2014). Language and Gender in English Language Teaching. The State of the University of Makassar: LTD, the US.

Riazi, A. (2007). A Student Case Study of Shiraz EFL Institutes. Asian EFL Journal, 9(1), 12-20.

Witteveen, L. (2009). The Voice of the Visual. Wageningen University: Wageningen.

Yule, G. (2010). The Study of Language ( $4^{\text {th }}$ Ed.). Cambridge University Press: the US. 